\title{
A Flexible Responsive Load Economic Model for Industrial Demands
}

\author{
Reza Sharifi ${ }^{1}$ (D), Amjad Anvari-Moghaddam ${ }^{2, *(D)}$, S. Hamid Fathi ${ }^{1}$ and Vahid Vahidinasab ${ }^{3}$ \\ 1 Electrical Engineering Department, Amirkabir University of Technology, Tehran 15916-34311, Iran; \\ reza.sharifi@aut.ac.ir (R.S.); fathi@aut.ac.ir (S.H.F.) \\ 2 Department of Energy Technology, Aalborg University, 9220 Aalborg East, Denmark \\ 3 Department of Electrical Engineering, Shahid Beheshti University, Tehran 19839-69411, Iran; \\ v_vahidinasab@sbu.ac.ir \\ * Correspondence: aam@et.aau.dk; Tel.: +45-9356-2062
}

Received: 18 February 2019; Accepted: 4 March 2019; Published: 8 March 2019

\begin{abstract}
The best pricing method for any company in a perfectly competitive market is the pricing scheme with regards to the marginal cost. In contrast to this environment, there is a market with imperfect competition. In this market, the price can be affected by some players in the generation/demand side (i.e., suppliers and/or buyers). In the economic literature, "market power" refers to a company that has the power to affect prices. In fact, market power is often defined as the ability to divert prices from competitive levels. In the electricity market, especially because of the integration of intermittent renewable energy resources (RESs) along with the inflexibility of demand, there are levels of market power on the supply side. Hence, implementation of demand response (DR) programs is necessary to increase the flexibility of the demand side to deal with the intermittency of renewable generations and at the same time tackle the market power of the supply side. This paper uses economic theories and mathematical formulations to develop a flexible responsive load economic model (FRLEM) based on real-time pricing (RTP) to show modification of the load profile and mitigation of the energy costs for an industrial zone. This model was developed based on constant elasticity of the substitution utility function, known as one of the most popular utility functions in microeconomics.
\end{abstract}

Keywords: demand-side management; economic demand response model; consumer utility function; electricity market restructuring

\section{Introduction}

The objective of demand-side management (DSM) in the industrial sector is to improve the profile of electrical loads by two means: (1) energy efficiency solutions; and (2) demand response (DR) programs. An energy efficiency solution reduces the electricity consumed to provide a certain service, with the primary goal of reducing electricity costs and protecting the environment. These programs reduce the total electricity consumption and peak electricity load with the help of energy-efficient equipment and other efficiency improvement means. These programs consist of activities such as installing thermal insulators, low-power equipment, and so on [1].

The DR program refers to a set of measures aimed at encouraging a voluntary change in the consumers' electricity usage pattern in response to changes in electricity prices or grid reliability conditions. The increase in the demand-side capacity following the participation in such programs could effectively reduce the electricity costs [2] and improve the robust operation of energy systems [3], as well as enhance system reliability [4,5]. The US Department of Energy has defined DR as changes in electric usage by end-use customers from their normal consumption patterns in response to changes in 
the price of electricity over time (passive participation), or to incentive payments (active participation) designed to induce lower electricity use at times of high wholesale market prices or when system reliability is jeopardized [6]. This DR definition is focused on the price of the wholesale market and the occurrence of power crises. However, what is important for consumers is the retailer's price, which includes the cost of energy transmission, distribution, and peripheral services. The Nordic Electricity Market has provided a more precise definition of DR as a voluntary temporary adjustment of electricity demand as a response to a price signal or a reliability-based action [7].

The DR programs are classified into two major categories and several subcategories, as shown in Figure 1 [8].

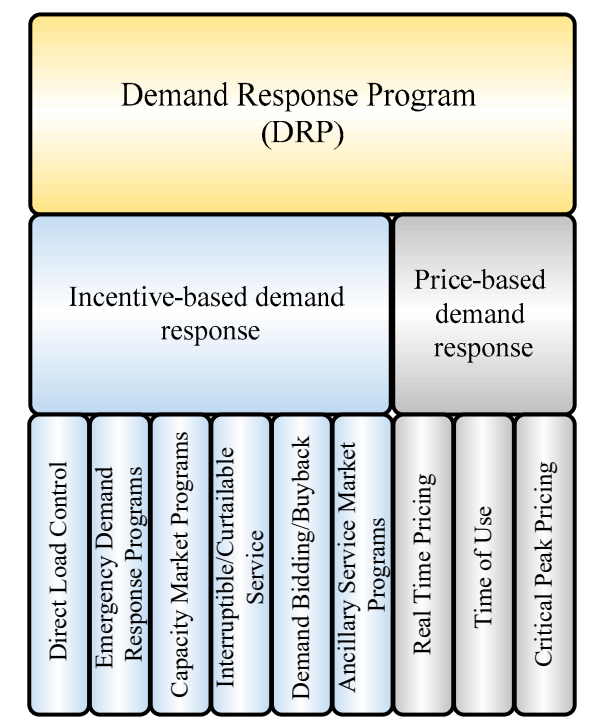

Figure 1. Classification of demand response (DR) programs.

In the industrial sector, electrical loads can be categorized into several groups in terms of their response to DR programs. In [9], these loads are divided into three categories:

- The loads related to production machinery and equipment that apply a variable force on a raw material over a defined cycle time (e.g., mechanical and hydraulic equipment, presses, welding equipment, etc.). These loads cannot be modified, but can be switched on/off when necessary. Therefore, these electrical loads can respond well to direct load curtailment commands while supporting demand-shifting-type DR programs.

- The loads related to production machinery and equipment that apply a steady continuous force to move fluids (e.g., pumps, fans, blowers, air compressors, etc.). The power consumption of these loads can be adjusted as needed, so they respond to all DR programs.

- The loads related to production machinery and equipment that change the phase, composition, or chemical properties of a raw material and run continuously unless stopped for maintenance. Any interruption or change in the power supply of such machinery may result in the failure of the production process or poor product quality. These loads never respond to DR programs.

According to the above-mentioned classification of electrical loads in the industrial sector, we can conclude that some of these electrical loads (known as flexible demand) may respond well to DR programs [9] However, there are several technical/operational challenges and obstacles ahead of the application of such programs in the industrial sector. These mainly include [10-12]:

- Absence of proper responsive load economic models,

- Poor understanding of the technical potentials of DR programs in the industrial sector,

- Insufficient economic returns of DR programs, 
- Inadequate time to adjust production or take action,

- Absence of smart platforms for reciprocal communication between retailers and end-use customers.

In general, access to a flexible responsive load economic model (FRLEM) greatly contributes to our knowledge about the impact of consumer participation in DR programs and their influence on the load profile [13-15]. Therefore, many such models have been developed for DR programs of different types, such as time of use (TOU), critical peak pricing (CPP), and real-time pricing (RTP)-based programs [16-20]. However, most of these models utilize the concept of price elasticity, which assumes the point elasticity as the price elasticity of demand at a particular point on the demand curve. In other words, these models linearize the demand curve at a specific operating point instead of considering the entire demand. This means that they consider the price elasticity of demand as a pre-known fixed value at a point on the demand curve. Since the price elasticity varies along the demand curve, this assumption creates a discontinuity in the decision-making process. Therefore, these models will not perform well for the industrial sector, where a given DR model is supposed to consider countless consumers with different loads [21,22].

In References [23,24], economic theories and mathematical formulations are used to present a novel model for TOU-based DR programs with effective market-oriented models for residential consumers to change their time of consumption (i.e., to achieve adjustability in the DR model). Application of DR programs for the operation management of energy hubs is investigated in Reference [25], where responsive thermal and electrical loads are presented with related temporal behavior. Authors in [26] presented a day-ahead multi-objective optimization model for a building energy management system under TOU price-based DR programs, which merges building-integrated photovoltaic with other generations to optimize the economy and occupants' comfort by the synergetic dispatch of source-load-storage. In [27], an incentive DR program is proposed to assist customers to participate in the program. The proposed plan provides tools that can help the customers' premises to take part in DR programs. Likewise, a multi-level demand charge, along with an RTP program and incentivized signals is proposed in [28] for the participation of thermal energy storage (TES)-integrated commercial buildings in DR programs. The findings demonstrate that the existence of TES in a commercial building could result in higher flexibility for joining DR programs, and so to further decrease energy costs while maintaining the level of comfort for residents.

In this paper, we use economic theories and mathematical formulations to develop an RLEM for RTP-based programs with 24-h time intervals. Our aim in this effort was to achieve a model with two primary features: adaptability and adjustability. Here, adaptability refers to the applicability of the proposed model to all types of consumers regardless of their response to the DR program. Moreover, since the operating plans of industrial consumers may vary depending on their policies, extensive disparity in the hours of power usage in the industrial sector might be needed. Because of this, the model to be developed for this sector has to be sufficiently adjustable, which is also considered in this work. In light of the reviewed literature, the contributions of this work can be summarized as:

- A novel model is presented based on economic theories and mathematical formulations to enable industrial customer response to RTP-based DR programs for cost minimization,

- An efficient framework is proposed for industrial load management by considering different levels of participation in DR programs,

- A working platform is introduced to support key functionalities of an industrial DR program known as adaptability and adjustability.

The rest of this paper is given as follows: Section 2 explains theory of consumer choice. Simulation results together with model validation under different test scenarios are presented in Section 3. Finally, Section 4 concludes the paper by summarizing the main results. 


\section{Theory of Consumer Choice}

As mentioned in the introductory part of the paper, a model to be used for an RTP-based DR program should be able to account for a wide range of customers by featuring both adaptability and adjustability. Many of the existing models are based on the concept of price elasticity of demand, which cannot meet these features in a continuous process, as required for RTP-based programs.

The theory of consumer choice is a well-known microeconomics theory that explores how consumers spend their economic resources according to their preferences and subject to their budget constraints. Two important instruments of this theory are the utility function and the budget constraint. The interactions of these functions and constraints determine how consumers make their spending decisions $[29,30]$.

The utility function is an economic concept that represents the interest in gaining greater returns. There is no specific method for formulating this function, and it is often derived through empirical methods. One of the most popular standard utility functions developed for microeconomic analyses is the constant elasticity of substitution (CES).

This function is widely popular among economists working on microeconomic problems, and is normally applied where there are several different commodities available for consumption. The CES utility function for $n$ commodities is [31]:

$$
U\left(X_{1}, X_{2}, X_{3}, \ldots, X_{n}\right)=\left(\sum_{i=1}^{n} \alpha_{i}^{1-\rho} X_{i}^{\rho}\right)^{\frac{1}{\rho}} \quad 0 \neq \rho \prec 1 \quad \sum_{i=1}^{n} \alpha_{i}=1 ; \alpha_{i}>0
$$

In the above formulation, $(\rho-1)^{-1}$ is the elasticity of substitution and $\alpha_{i}$ denotes the share factors.

To expand this function to the electricity market, we assume that electrical energy with a specific price $P_{1}$ is considered as a commodity $\left(X_{1}\right)$, and electrical energy at a specific price of $P_{2}$ is considered as a commodity $\left(X_{2}\right)$. Thus, assuming $n$ electricity price levels for a $24-h$ period, we will have $n$ commodities.

Parameter $\rho$ determines the consumer's desire to participate in DR program. The greater the value of $\rho$, the more willing the customer will be to participate in DR program. This parameter also provides the first feature of a worthy DR model, known as adaptability. This means that by changing/fine-tuning this parameter, a broad range of customers in the electricity market can be considered. In the same way, parameter $\alpha_{i}$ (or share factors) accounts for adjustment of consumption ratio over the time in accordance with the customer's request. That is, changing the $\alpha_{i}$ parameter provides a new arrangement of the consumption in each hour. This enables the model to account for adjusting the amount of consumption in every time interval, which is the second feature of a worthy DR model, known as adjustability of consumption levels. From now on, parameter $\rho$ is named as the adaptability parameter while $\alpha_{i}$ is named as the adjustability parameter.

In the theory of consumer choice, consumer's spending decisions are subject to budget constraints. This theory considers the consumer behavior as a maximization problem where the goal is to obtain the highest profit from limited resources. Since a consumer's desire for making more profit is unlimited, the only factor that limits consumption is the limited budget. Therefore, the utility function subject to the budget constraint is:

$$
\begin{aligned}
& U\left(C_{1}, C_{2}, C_{3}, \ldots, C_{24}\right) \\
& \text { s.t. } \quad \mathrm{B}=\sum_{i=1}^{24}\left(C_{i} \cdot P_{i}\right)
\end{aligned}
$$


Here, it is assumed that the consumer adjusts their flexible power consumptions $\left(C_{i}\right)$ according to the pricing scheme. Therefore, the consumer aims to maximize the following utility function:

$$
\begin{aligned}
& \operatorname{Max}\left\{U\left(C_{1}, C_{2}, C_{3}, \ldots, C_{24}\right)=\left(\sum_{i=1}^{24} \alpha_{i}^{1-\rho} C_{i}^{\rho}\right)^{\frac{1}{\rho}}\right\} ; \quad 0 \neq \rho \prec 1 ; \quad \sum_{i=1}^{n} \alpha_{i}=1 ; \quad \alpha_{i}>0 \\
& \text { s.t. } \quad \mathrm{B}=\sum_{i=1}^{24}\left(C_{i} \cdot P_{i}\right)
\end{aligned}
$$

According to the method of Lagrange multipliers [32]:

$$
L=\left(\sum_{i=1}^{24} \alpha_{i}^{1-\rho} C_{i}^{\rho}\right)^{\frac{1}{\rho}}+\lambda\left[\mathrm{B}-\sum_{i=1}^{24} C_{i} \cdot P_{i}\right]
$$

The partial derivatives of Equation (4) with respect to any $C_{i}$ and $\lambda$ are given by:

$$
\begin{gathered}
\frac{d L}{d C_{i}}=\alpha_{i}^{1-\rho} C_{i}^{\rho-1} \cdot\left(\sum_{j=1}^{24} \alpha_{j}^{1-\rho} C_{j}^{\rho}\right)^{\frac{1-\rho}{\rho}}-\lambda P_{i}=0 \Rightarrow \lambda P_{i}=\alpha_{i}^{1-\rho} C_{i}^{\rho-1} \cdot\left(\sum_{j=1}^{24} \alpha_{j}^{1-\rho} C_{j}^{\rho}\right)^{\frac{1-\rho}{\rho}} \\
\frac{d L}{d \lambda}=\mathrm{B}-\sum_{i=1}^{24} C_{i} \cdot P_{i}=0
\end{gathered}
$$

Taking (5) and (6) into account, one can easily conclude that:

$$
\begin{aligned}
& C_{2}=\frac{\alpha_{2}}{\alpha_{1}}\left(\frac{P_{2}}{P_{1}}\right)^{\frac{1}{\rho-1}} \cdot C_{1} \\
& C_{3}=\frac{\alpha_{3}}{\alpha_{1}}\left(\frac{P_{3}}{P_{1}}\right)^{\frac{1}{\rho-1}} \cdot C_{1} \\
& \vdots \\
& C_{24}=\frac{\alpha_{24}}{\alpha_{1}}\left(\frac{P_{24}}{P_{1}}\right)^{\frac{1}{\rho-1}} \cdot C_{1}
\end{aligned}
$$

By substituting the relations extracted from (7) into (6), we arrive at:

$$
\begin{gathered}
\mathrm{B}=C_{1} \cdot P_{1}+\frac{\alpha_{2}}{\alpha_{1}}\left(\frac{P_{2}}{P_{1}}\right)^{\frac{1}{\rho-1}} \cdot C_{1} \cdot P_{2}+\frac{\alpha_{3}}{\alpha_{1}}\left(\frac{P_{3}}{P_{1}}\right)^{\frac{1}{\rho-1}} \cdot C_{1} \cdot P_{3}+\ldots \ldots \ldots+\frac{\alpha_{24}}{\alpha_{1}}\left(\frac{P_{24}}{P_{1}}\right)^{\frac{1}{\rho-1}} \cdot C_{1} \cdot P_{24} ; \\
\Rightarrow C_{1}=\frac{\mathrm{B}}{P_{1}+\frac{\alpha_{2}}{\alpha_{1}}\left(\frac{P_{2}}{P_{1}}\right)^{\frac{1}{\rho-1}} \cdot P_{2}+\ldots+\frac{\alpha_{24}}{\alpha_{1}}\left(\frac{P_{24}}{P_{1}}\right)^{\frac{1}{\rho-1}} \cdot P_{24}}
\end{gathered}
$$

Assuming $\Omega$ as the denominator of the above formulation, we have:

$$
\Omega=P_{1}+\frac{\alpha_{2}}{\alpha_{1}}\left(\frac{P_{2}}{P_{1}}\right)^{\frac{1}{\rho-1}} \cdot P_{2}+\frac{\alpha_{3}}{\alpha_{1}}\left(\frac{P_{3}}{P_{1}}\right)^{\frac{1}{\rho-1}} \cdot P_{3}+\ldots \ldots \ldots+\frac{\alpha_{24}}{\alpha_{1}}\left(\frac{P_{24}}{P_{1}}\right)^{\frac{1}{\rho-1}} \cdot P_{24}
$$

Therefore, the load model for a 24-h daily period in the presence of an RTP-based DR program is:

$$
\left.\begin{array}{l}
C_{1}=\frac{\mathrm{B}}{\Omega} \\
C_{2}=\frac{\alpha_{2}}{\alpha_{1}}\left(\frac{P_{2}}{P_{1}}\right)^{\frac{1}{\rho-1}} \cdot \frac{\mathrm{B}}{\Omega} \\
\vdots \\
C_{24}=\frac{\alpha_{24}}{\alpha_{1}}\left(\frac{P_{24}}{P_{1}}\right)^{\frac{1}{\rho-1}} \cdot \frac{\mathrm{B}}{\Omega}
\end{array}\right\} \Rightarrow\left(\begin{array}{c}
C_{h}=\frac{\alpha_{h}}{\alpha_{1}}\left(\frac{P_{h}}{P_{1}}\right)^{\frac{1}{\rho-1}} \cdot \frac{\mathrm{B}}{\Omega} \\
h=1,2, \ldots, 24
\end{array}\right)
$$


Since the industrial production in any industrial zone is directly related to their electricity usage, there is no difference between the total electricity consumed over a 24-h period before and after the implementation of the DR program. In other words, the change will be in the pattern (hours) of consumption, not in the total power consumed, which means:

$$
C_{\text {primary }}=\sum_{h=1}^{24} C_{h}=\sum_{h=1}^{24} \frac{\alpha_{h}}{\alpha_{1}}\left(\frac{P_{h}}{P_{1}}\right)^{\frac{1}{\rho-1}} \cdot \frac{\mathrm{B}}{\Omega}
$$

where $C_{\text {primary }}$ is total electricity consumed before the DR program.

$$
\mathrm{B}=\frac{\Omega \cdot C_{\text {primary }}}{\sum_{h=1}^{24} \frac{\alpha_{h}}{\alpha_{1}}\left(\frac{P_{h}}{P_{1}}\right)^{\frac{1}{\rho-1}}}
$$

By substituting (12) into (10), it can be deduced that:

$$
C_{h}=\frac{\alpha_{h}}{\alpha_{1}}\left(\frac{P_{h}}{P_{1}}\right)^{\frac{1}{\rho-1}} \cdot \frac{C_{\text {primary }}}{\sum_{h=1}^{24} \frac{\alpha_{h}}{\alpha_{1}}\left(\frac{P_{h}}{P_{1}}\right)^{\frac{1}{\rho-1}}}
$$

As shown in (13), the demand for each hour $C_{h}$ is a function of budget $\mathrm{B}$, price $P_{h}$, adjustability parameters $\alpha_{h}$, and adaptability parameter $\rho$. The consumers' budget is limited and prices are determined by market mechanism and retailers. Thus, the parameters related to the customer are $\rho$ and $\alpha_{h}$. These parameters decide the extent of consumer participation in the DR program, and can be used to estimate how the consumer responds to such programs.

\section{Performance Evaluation}

In this section, we examine the performance of the proposed model. The load profile used for this purpose (Figure 2) belongs to an industrial zone that was adopted from [33].

In this industrial zone, as shown in Table 1, operation of industrial units is continuous and are scheduled in three shifts per day [34]. Also, the electric energy demand is divided into non-flexible and flexible parts. In each work shift, it is assumed that the minimum demand relates to the non-flexible part while the rest of the electrical demand relates to the flexible loads. Hence, we are only able to manage the flexible part of the demand to reduce the cost of purchasing electrical energy.

Table 1. Work shifts.

\begin{tabular}{ccc}
\hline Day Shift & Evening Shift & Night Shift \\
\hline 08:00-15:00 & $16: 00-23: 00$ & $00: 00-07: 00$ \\
\hline
\end{tabular}

Note that the work shift times can affect the cost of a company. In general, employers pay a premium to the night-shift workers. Hence, there is less willingness to engage workers in the night shift from the company owner's perspective. Since the cost of paying for night-shift workers may be higher than the cost of electricity, there should be a trade-off between these two. The proposed DR model in this paper could also address this issue with the help of the adjustability parameters $\alpha$. Wages are assumed to be constant for any time within a given work shift. 
Therefore, the values of adjustability parameters $\alpha_{h}$ are considered different among different work shifts while remaining unchanged within a work shift, that is:

$$
\begin{cases}\alpha_{\text {day }}=\alpha_{h_{1}} & h \in 08: 00-15: 00 \\ \alpha_{\text {evening }}=\alpha_{h_{2}} & h \in 16: 00-23: 00 \\ \alpha_{\text {night }}=\alpha_{h_{3}} & h \in 00: 00-07: 00\end{cases}
$$

As an example, the condition $\alpha_{\text {day }}>\alpha_{\text {night }}$ denotes that the company owner's desire to use electrical energy for the day shift is higher than for the night shift. On the other hand, when $\alpha_{\text {day }}=\alpha_{\text {evening }}=\alpha_{\text {night }}$, the industrial DR participant demonstrates a homogeneous behavior along the day, meaning that there is no difference among the work shifts from the company owner's viewpoint.

In the following sections, the effectiveness of this model is validated under two case studies.

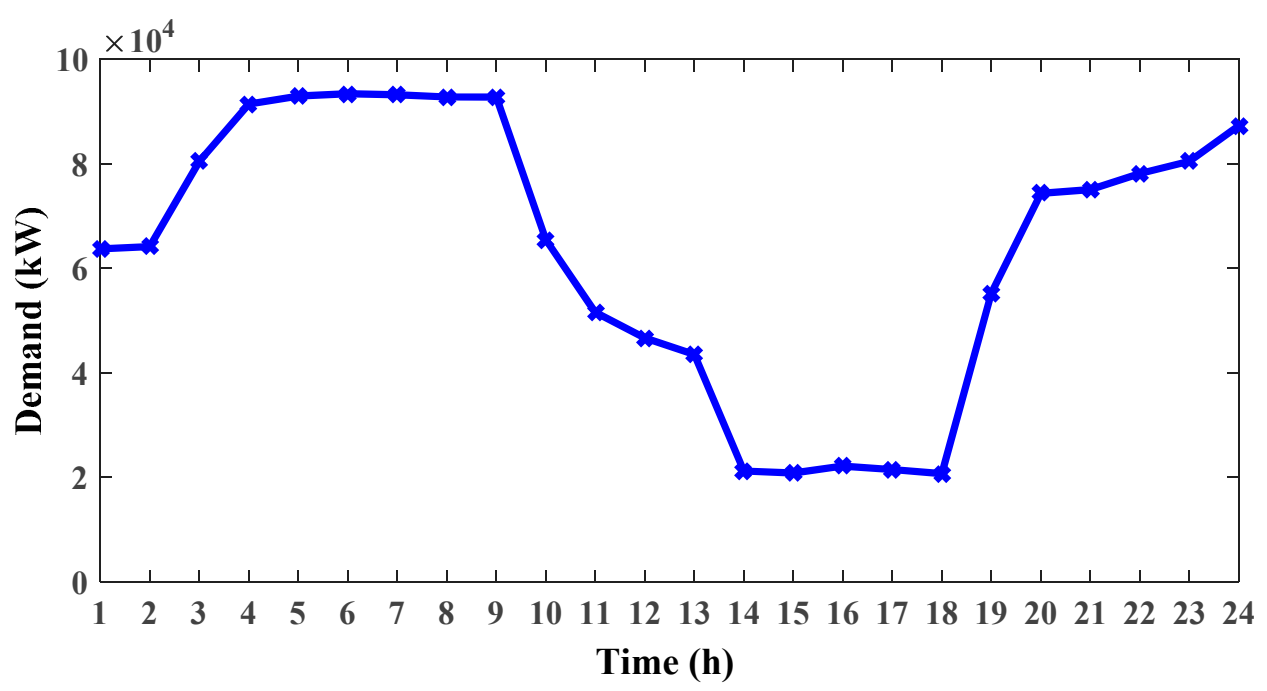

Figure 2. Load profile used in the evaluation.

\subsection{Case I}

In the first case, we simulated four scenarios, illustrated in Table 2. In the first scenario simulation, customers (e.g., industrial plants) showed no response to price changes, that is, there was no participation on the part of consumers. In the next three scenarios, consumers participated by the amounts shown in the third column of Table 2. As stated earlier, the higher the $\rho$ value, the greater the participation of customers in the DR program. The following assumptions were also made for the aforementioned scenarios:

(a) The price signal for the examined industrial zone was provided in two ways (Note: in both pricing methods, the average price was the same for over $24 \mathrm{~h}$ ):

(1) RTP pricing (as shown in Figure 3a, belongs to the date 28 August 2017, available in [35]);

(2) TOU pricing according to work shifts (as shown in Figure $3 \mathrm{~b}$ );

(b) The adjustability parameters values were the same for all work shifts, that is, $\alpha_{\text {day }}=\alpha_{\text {evening }}=\alpha_{\text {night }}$. 
Table 2. Performance evaluation of the proposed model in different scenarios. RTP: real-time pricing; TOU: time of use.

\begin{tabular}{cccccc}
\hline No. & Program & $\begin{array}{c}\text { Partnership } \\
\text { Level }\end{array}$ & $\begin{array}{c}\text { Energy Consumption } \\
\text { (MW) }\end{array}$ & $\begin{array}{c}\text { Budget } \\
\text { (Euro/kW) }\end{array}$ & $\begin{array}{c}\text { Budget } \\
\text { Change (\%) }\end{array}$ \\
\hline \multirow{2}{*}{1} & TOU & - & 1528 & 69,064 & base \\
& RTP & & 1528 & 71,508 & base \\
\hline \multirow{2}{*}{2} & TOU & \multirow{2}{*}{0.3} & 1528 & 63,906 & -8.07 \\
& RTP & & 1528 & 63,273 & -13.01 \\
\hline \multirow{2}{*}{3} & TOU & \multirow{2}{*}{0.5} & 1528 & 62,769 & -10.02 \\
& RTP & & 1528 & 62,045 & -15.25 \\
\hline \multirow{2}{*}{4} & TOU & \multirow{2}{*}{0.8} & 1528 & 59,254 & -16.55 \\
& RTP & & 1528 & 58,433 & -22.37 \\
\hline
\end{tabular}

The results obtained by modelling of the scenarios are presented in Table 2. As the fourth column of this table shows, all scenarios had the same total energy consumption. This is consistent with our second assumption, which states that industrial units do not reduce their total energy usage but shift the usage from high-price hours to low-price hours to minimize their electricity bill without altering their output.

According to the budget column of the first scenario in Table 2, the RTP program had greater cost implications for customers than TOU program. This is a realistic result, as implementation of RTP program is more likely to transfer the risk of the wholesale market from retailers to consumers.

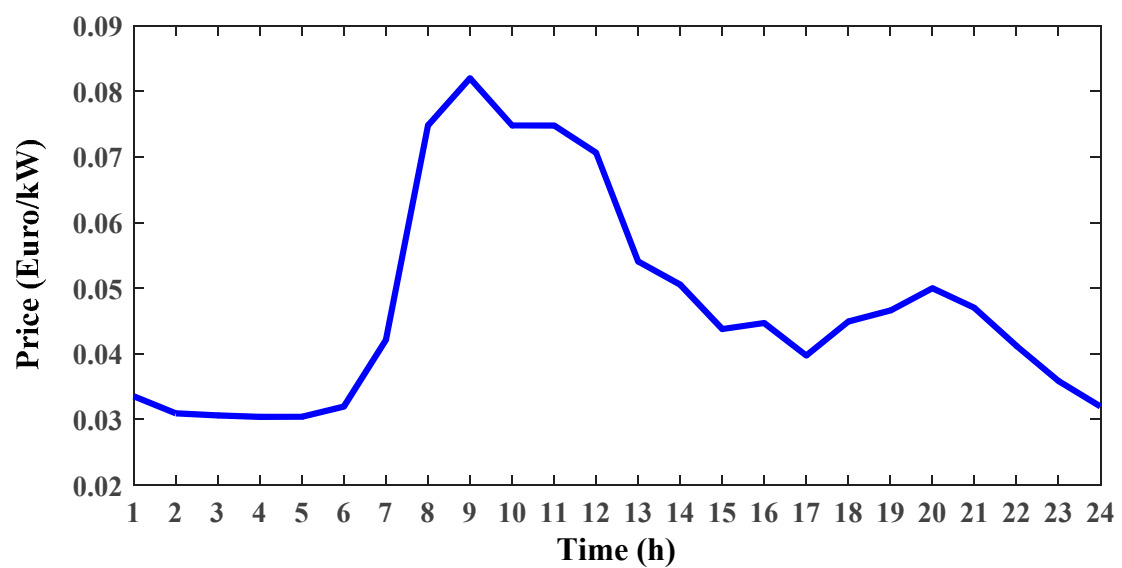

(a)

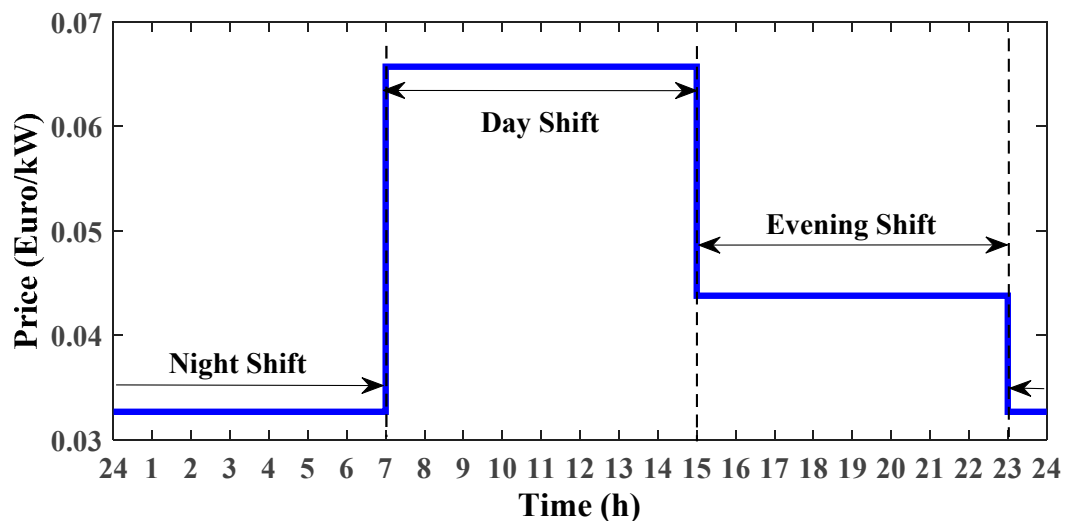

(b)

Figure 3. Electricity prices according to (a) real-time pricing (RTP) pricing; (b) time of use (TOU) pricing. 
In scenario No. 2, although both RTP and TOU programs were modelled with the same participation level $(\rho=0.3)$, the customer's electricity budget in RTP was less than in TOU.

This was also true for the reduction in electricity budget, meaning that even a low participation in the RTP program resulted in a lower electricity budget compared to the base scenario and TOU.

An examination of Table 2 also reveals similar results for scenarios No. 3 and 4 . However, as the participation rates assumed in these scenarios were greater than before, the consequent reductions in electricity budget were more significant, which implies that industrial customers can reduce their electricity bill without reducing their consumption.

To get a better insight into the level of commitment in industrial DR programs over the work shifts, the load profiles are plotted in Figures 4 and 5 for the different scenarios in Table 2. It can be observed that with the increase of $\rho$, the consumer's wish to take part in DR programs, especially during the night shift, increased, as the price of electric energy is low. This effect is clearly illustrated in Figure 5 for each time interval.

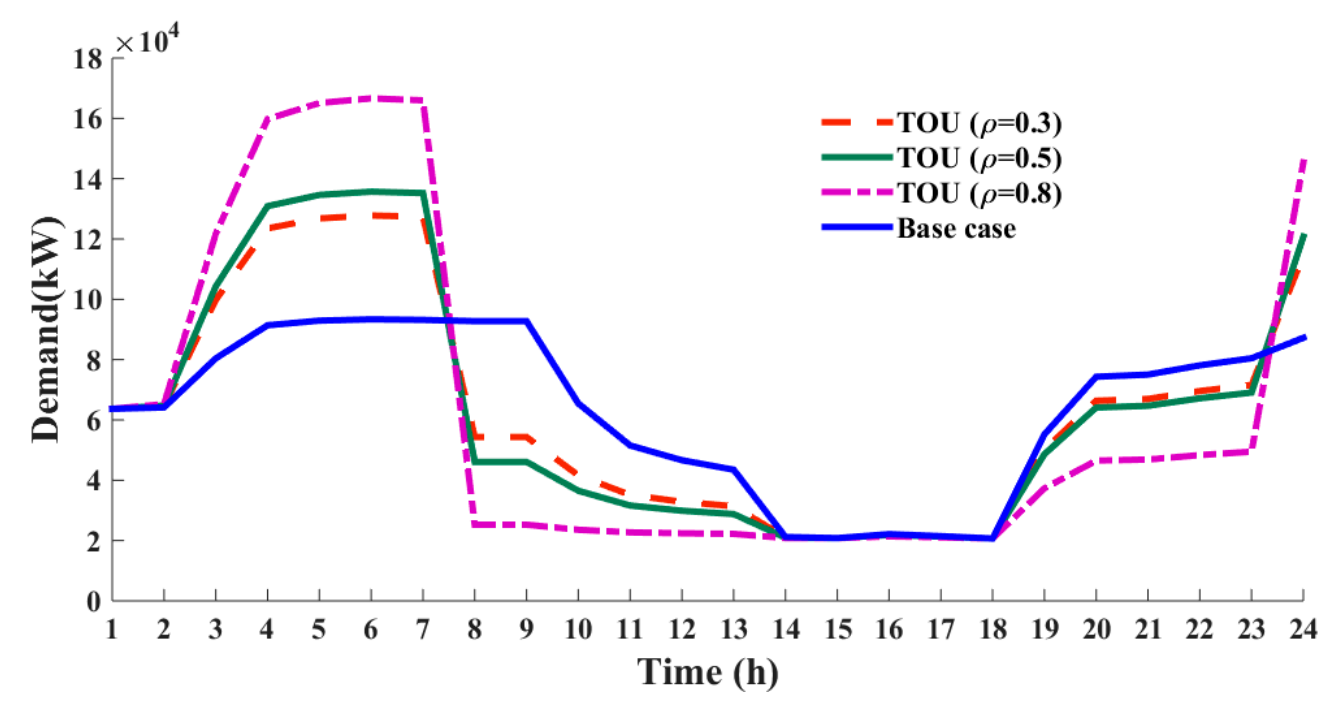

Figure 4. The impact of TOU programs on load profile.

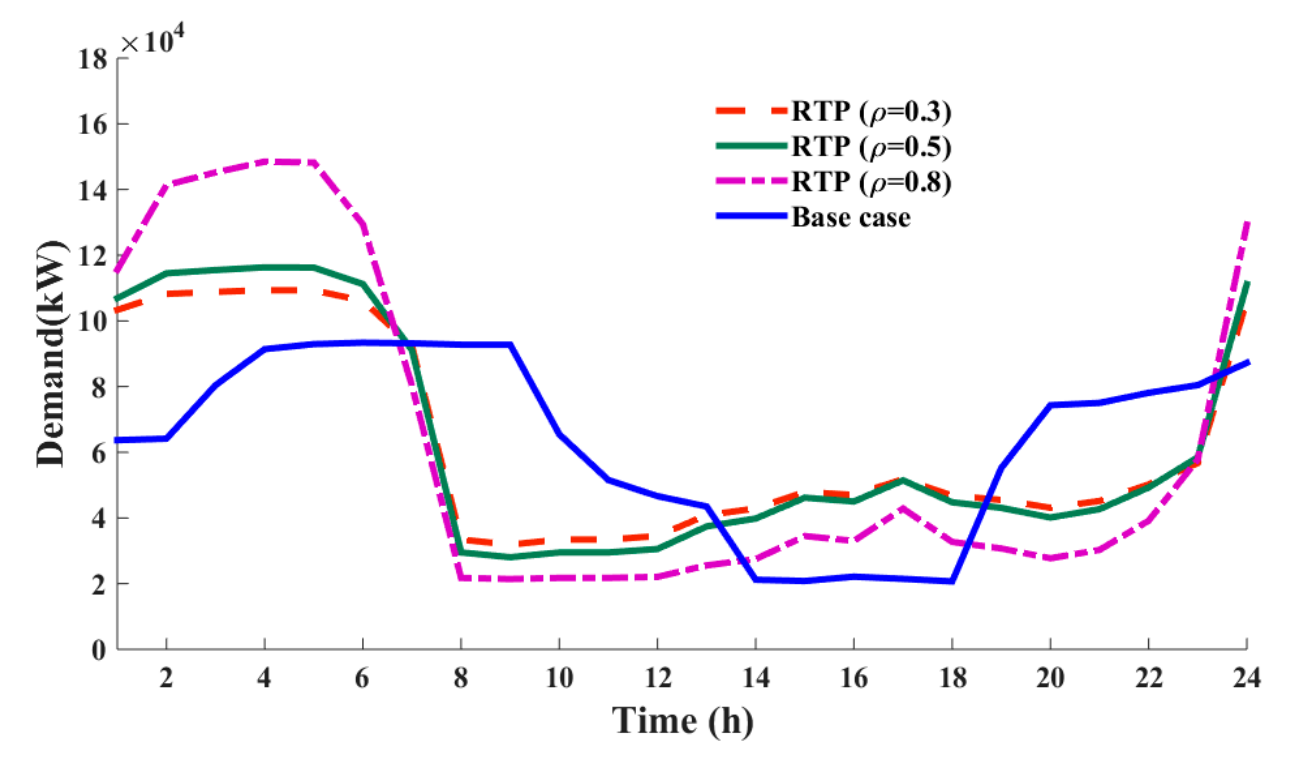

Figure 5. The impact of RTP programs on load profile. 


\subsection{Case II}

Table 3 shows the changes in the budget and demand for adaptability parameter $\rho$ and adjustability parameters $\alpha=\left(\alpha_{\text {day }}, \alpha_{\text {evening, }}, \alpha_{\text {night }}\right)$.

In Table 3 for a given $\rho$, when $\alpha_{\text {day }}=\alpha_{\text {evening }}=\alpha_{\text {night }}$, as mentioned before, there was no difference between the work shifts. Because of this, consumption shifted to a night shift when the price of electrical energy was low. On the other hand, different behavioral patterns during a given working day could be emulated by considering different adjustability values. As an example, in row 3 of Table 3 , $\alpha_{\text {day }}=1.1 \times \alpha_{\text {evening }}$ and $\alpha_{\text {day }}=1.3 \times \alpha_{\text {night }}$, which denotes that the company owner's desire to use electrical energy for the day shift was higher than the evening shift and much higher than the night shift. Since the price of electrical energy for the day shift is higher than other shifts, the amount of required budget is increased relative to the previous state.

In Table 3 for a given $\alpha$, an increase in $\rho$ (and consequently consumers' participation) led to a decrease in the budget, which reflects the consumer's tendency to move towards more participation in the DR program. As mentioned and shown in Table 3, the total daily power consumption in the absence and presence of DR action remained the same and only shifted among different working hours.

As shown in Figures 6 and 7, the required budget and day shift consumption was reduced by increasing the level of participation $\rho$. On the other hand, with the increase of the adjustability parameters $\alpha_{d a y}$ for the day shift (which means an increase in the inclination of electricity consumption for day shift with high energy prices), the amount of the budget and day-shift consumption also increased.

The results obtained for DR model during the night shift are shown in Figure 8. As can be seen, with the increase of $\rho$, there was a growing inclination in the power consumption of this shift due to the lower electricity prices. In a like manner, with the increase of the adjustability parameters $\alpha_{\text {night }}$, the consumption tendency increased at the night shift.

Table 3. Changes in the budget and demand.

\begin{tabular}{cccc}
\hline Scenario & \multicolumn{3}{c}{ Budget (Euro) and Demand (kW) } \\
\cline { 2 - 4 } & $\boldsymbol{\rho}=\mathbf{0 . 3}$ & $\boldsymbol{\rho}=\mathbf{0 . 5}$ & $\boldsymbol{\rho}=\mathbf{0 . 8}$ \\
\hline base case-without DR & & 71,508 and 1528 \\
$\alpha_{\text {day }}=\alpha_{\text {evening }}=\alpha_{\text {night }}$ & 63,273 and 1528 & 62,045 and 1528 & 58,433 and 1528 \\
$\alpha_{\text {day }}=1.1 \times \alpha_{\text {evening }}$ and $\alpha_{\text {day }}=1.3 \times \alpha_{\text {night }}$ & 64,046 and 1528 & 62,727 and 1528 & 58,741 and 1528 \\
\hline
\end{tabular}

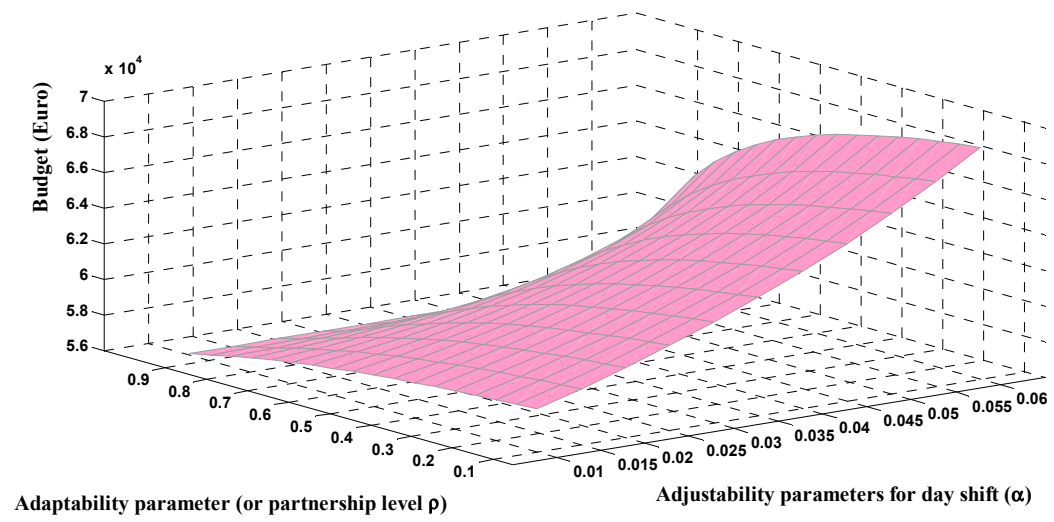

Figure 6. Changes in the budget for different values of adaptability and adjustability parameters.

As can be seen from the simulation results, the introduction of the two mentioned control parameters in an industrial DR action creates a strong tool to adjust the amount of participation and consumption according to customer preferences. So, the proposed DR model is able to reconcile to 
different customers with different flexibilities against prices, and allows the consumption levels to be adjusted over different work shifts.

This section may be divided by subheadings. It should provide a concise and precise description of the experimental results, their interpretation, as well as the experimental conclusions that can be drawn.

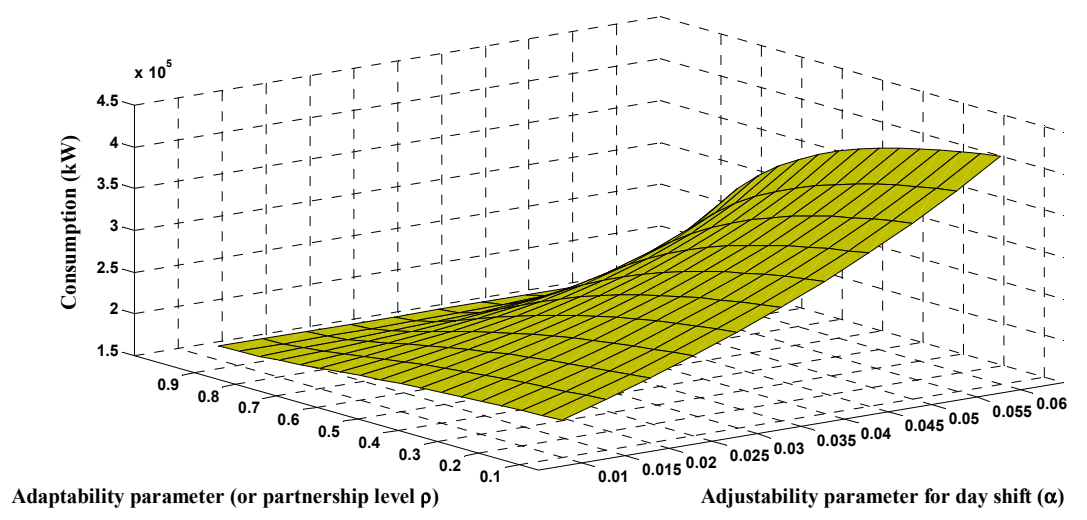

Figure 7. Changes in the day-shift consumption for different values of adaptability and adjustability parameters.

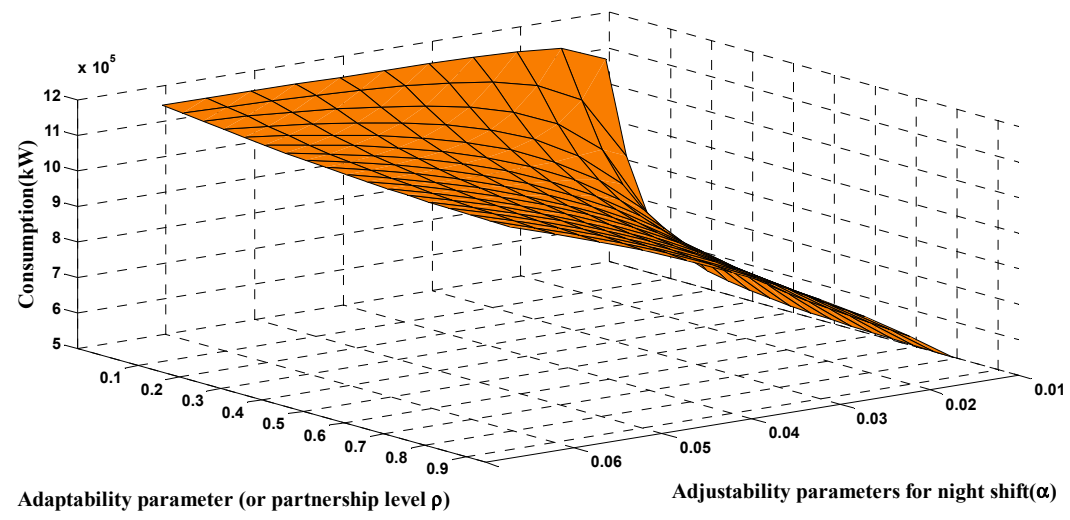

Figure 8. Changes in the night-shift consumption for different values of adaptability and adjustability parameters.

\section{Conclusions}

The development of flexible responsive load economic models is an important requirement for the proper evaluation of the consumer participation impact on load profiles. In this paper, economic models and mathematical formulation were used to develop a new economic model for RTP-based DR programs. Compared to the existing models reported in the same area, the model presented in this paper was able to integrate consumers' tendency to modify the load profile and reallocate the consumption at any time. This feature enabled the DR model to be customized for every type of consumer with different preferences. Unlike the previous DR models, which are mainly based on the concept of price elasticity at a specific operating point, the proposed model considered the whole demand curve modelling for DR actions. Additionally, the presented model demonstrated that the classical economic decision-making process for each consumer can be applied. In this way, the decision maker can identify and assess all possible options and consequences of DR implementation and select the most logical way of doing so. For example, retailers can use this model to build optimal bidding curves or help network operators get the information they need about responding to the DR program in order to determine network tariffs that are appropriate for managing congestions. It was also 
demonstrated that the proposed model enables system operators to investigate the impact of different participation levels on the aggregated load profile.

Author Contributions: Conceptualization, R.S.; methodology, R.S., A.A.-M.; software, R.S.; resources, A.A.-M., S.H.F., and V.V.; writing—original draft preparation, R.S.; writing—review and editing, A.A.-M., V.V.; supervision, A.A.-M., S.H.F., and V.V.

Funding: This research received no external funding.

Conflicts of Interest: The authors declare no conflict of interest.

\section{References}

1. Sharifi, R.; Fathi, S.H.; Vahidinasab, V. A review on demand-side tools in electricity market. Renew. Sustain. Energy Rev. 2017, 72, 1-7. [CrossRef]

2. Wang, Y.; Wang, Y.; Yujing, H.; Yu, H.; Du, R.; Zhang, F.; Zhang, F.; Zhu, J. Optimal Scheduling of the Regional Integrated Energy System based on energy price Demand Response. IEEE Trans. Sustain. Energy 2018. [CrossRef]

3. Majidi, M.; Mohammadi-Ivatloo, B.; Anvari-Moghaddam, A. Optimal robust operation of combined heat and power systems with demand response programs. Appl. Therm. Eng. 2019, 149, 1359-1369. [CrossRef]

4. Vahedipour-Dahraie, M.; Anvari-Moghaddam, A.; Guerrero, J.M. Evaluation of reliability in risk-constrained scheduling of autonomous microgrids with demand response and renewable resources. IET Renew. Power Gener. 2018, 12, 12657-12667. [CrossRef]

5. Amini, M.; Almassalkhi, M. Investigating delays in frequency-dependent load control. In Proceedings of the 2016 IEEE Innovative Smart Grid Technologies-Asia (ISGT-Asia), Melbourne, Australia, 28 November-1 December 2016; pp. 448-453.

6. Safdarian, A.; Fotuhi-Firuzabad, M.; Lehtonen, M. Impacts of time-varying electricity rates on forward contract scheduling of DisCos. IEEE Trans. Power Deliv. 2014, 29, 733-741. [CrossRef]

7. THEMA Consulting Group: “Demand Response in the Nordic Electricity Market-Input to Strategy on Demand Flexibility. TemaNord 2014, 553. Available online: http://www.nordicenergy.org/wp-content/ uploads/2014/10/Demand-response-in-the-Nordic-electricity-market.pdf (accessed on 21 March 2016). [CrossRef]

8. Willis, H.L.; Powell, R.W.; Tram, H.N. Computerized methods for analysis of impact of demand side management on distribution systems. IEEE Trans. Power Deliv. 1987, 2, 1236-1243. [CrossRef]

9. Starke, M.; Alkadi, N.; Ma, O. Assessment of Industrial Load for Demand Response Across US Regions of the Western Interconnect. No. ORNL/TM-2013/407; ORNL/DOE, September 2013. Available online: https:/ /info.ornl.gov/sites/publications/Files/Pub45942.pdf (accessed on 7 November 2016).

10. Sharifi, R.; Fathi, S.H.; Vahidinasab, V. Customer baseline load models for residential sector in a smart-grid environment. Energy Rep. 2016, 2, 74-81. [CrossRef]

11. Bhattarai, B.P.; Lévesque, M.; Bak-Jensen, B.; Pillai, J.R.; Maier, M.; Tipper, D.; Myers, K.S. Design and cosimulation of hierarchical architecture for demand response control and coordination. IEEE Trans. Ind. Inform. 2017, 13, 1806-1816. [CrossRef]

12. Pinson, P.; Madsen, H. Benefits and challenges of electrical demand response: A critical review. Renew. Sustain. Energy Rev. 2014, 39, 686-699.

13. Aalami, H.A.; Parsa-Moghaddam, M.; Yousefi, G.R. Modelling and prioritizing demand response programs in power markets. Electr. Power Syst. Res. 2010, 80, 426-435. [CrossRef]

14. Ashot, M.; Kennedy, S.W. A novel demand response model with an application for a virtual power plant. IEEE Trans. Smart Grid. 2015, 6, 230-237.

15. Deng, R.; Yang, Z.; Chow, M.Y.; Chen, J. A survey on demand response in smart grids: Mathematical models and approaches. IEEE Trans. Ind. Inform. 2015, 11, 570-582. [CrossRef]

16. Kai, M.; Hu, G.; Spanos, C.J. A cooperative demand response scheme using punishment mechanism and application to industrial refrigerated warehouses. IEEE Trans. Ind. Inform. 2015, 11, 1520-1531.

17. Sharifi, R.; Anvari-Moghaddam, A.; Fathi, S.H.; Guerrero, J.M.; Vahidinasab, V. Dynamic pricing: An efficient solution for true demand response enabling. J. Renew. Sustain. Energy 2017, 9, 065502. [CrossRef] 
18. Vahedipour-Dahraie, M.; Rashidizadeh-Kermani, H.; Najafi, H.R.; Anvari-Moghaddam, A.; Guerrero, J.M. Stochastic security and risk-constrained scheduling for microgrid with demand response and renewable energy resources. IET Gener. Transm. Distrib. 2017, 11, 1812-1821. [CrossRef]

19. Xu, F.Y.; Loi, L.L. Novel active time-based demand response for industrial consumers in smart grid. IEEE Trans. Ind. Inform. 2015, 11, 1564-1573. [CrossRef]

20. Huang, X.; Hong, S.H.; Li, Y. Hour-ahead price based energy management scheme for industrial facilities. IEEE Trans. Ind. Inform. 2017, 132886-132898. [CrossRef]

21. Mohajeryami, S.; Moghaddam, I.N.; Doostan, M.; Vatani, B.; Schwarz, P. A novel economic model for price-based demand response. Electr. Power Syst. Res. 2016, 135, 1-9. [CrossRef]

22. Vahedipour-Dahraie, M.; Najafi, H.; Anvari-Moghaddam, A.; Guerrero, J. Study of the Effect of Time-Based Rate Demand Response Programs on Stochastic Day-Ahead Energy and Reserve Scheduling in Islanded Residential Microgrids. Appl. Sci. 2017, 7, 378. [CrossRef]

23. Sharifi, R.; Anvari-Moghaddam, A.; Fathi, S.H.; Guerrero, J.M.; Vahidinasab, V. Economic demand response model in liberalised electricity markets with respect to flexibility of consumers. IET Gener. Transm. Distrib. 2017, 11, 4291-4298. [CrossRef]

24. Sharifi, R.; Anvari-Moghaddam, A.; Fathi, S.H.; Guerrero, J.M.; Vahidinasab, V. An optimal market-oriented demand response model for price-responsive residential consumers. Energy Effic. 2018, 1-3. [CrossRef]

25. Alipour, M.; Zare, K.; Abapour, M. MINLP probabilistic scheduling model for demand response programs integrated energy hubs. IEEE Trans. Ind. Inform. 2018, 14, 79-88. [CrossRef]

26. Wang, F.; Zhou, L.; Ren, H.; Liu, X.; Talari, S.; Shafie-khah, M.; Catalão, J.P. Multi-objective optimization model of source-load-storage synergetic dispatch for building energy system based on TOU price demand response. IEEE Trans. Ind. Appl. 2018, 54, 1017-1028. [CrossRef]

27. Eissa, M.M. Developing incentive demand response with commercial energy management system (CEMS) based on diffusion model, smart meters and new communication protocol. Appl. Energy 2019, 236, 273-292. [CrossRef]

28. Cao, Y.; Du, J.; Soleymanzadeh, E. Model predictive control of commercial buildings in demand response programs in the presence of thermal storage. J. Clean. Prod. 2019, 218, 315-327. [CrossRef]

29. Thaler, R. Toward a positive theory of consumer choice. J. Econ. Behav. Organ. 1980, 1, 39-60. [CrossRef]

30. Lancaster, K.J. A new approach to consumer theory. J. Political Econ. 1966, 72, 132-157. [CrossRef]

31. Uzawa, H. Production functions with constant elasticities of substitution. Rev. Econ. Stud. 1962, 29, $291-299$. [CrossRef]

32. Bellman, R. Dynamic programming and Lagrange multipliers. Proc. Natl. Acad. Sci. USA 1956, 42, 767-769. [CrossRef]

33. Tao, H.; Pinson, P.; Fan, S. Global energy forecasting competition 2012. Int. J. Forecast. 2014, 30, $357-363$.

34. Geliebter, A.; Gluck, M.E.; Tanowitz, M.; Aronoff, N.J.; Zammit, G.K. Work-shift period and weight change. Nutrition 2000, 16, 27-29. [CrossRef]

35. NordPool. Price Calculation. Available online: http://nordpoolspot.com/Market-data1/Dayahead/AreaPrices / ALL1/H (accessed on 13 October 2016).

(C) 2019 by the authors. Licensee MDPI, Basel, Switzerland. This article is an open access article distributed under the terms and conditions of the Creative Commons Attribution (CC BY) license (http://creativecommons.org/licenses/by/4.0/). 